\title{
Solução estrutural de galpão em aço
}

\author{
Structural steel shed solution \\ Solución de cobertizo de acero estructural
}

\section{Resumo}

No Brasil, um dos materiais mais utilizados na construção civil é o aço, pois apresenta uma série de vantagens como: elevada resistência; elevada ductibilidade; alto grau de confiança; canteiro de obras menor e mais organizado; apresenta grande facilidade de reforço e ampliação; rapidez de execução. A maior parte das construções em aço são de estruturas horizontais, com um único pavimento. Os galpões compõem grande parte dessa parcela, com soluções mais versáteis e econômicas que proporcionam grandes vãos livres, com alto grau de responsabilidade, no qual requer atenção especial e sendo indispensável de ser realizado por profissional capacitado. Tendo em vista a demanda por profissionais qualificados e o grande crescimento do uso do aço como sistema estrutural na construção civil, este trabalho busca oferecer um roteiro de projeto para estrutura de aço de um galpão típico na região de Caruaru - PE, no qual se utiliza perfis formado a frio (PFF) no sistema de cobertura e perfis laminado a quente para os pilares. Será utilizado o software SAP2000 para a modelagem e análise estrutural do galpão, promovendo o procedimento adequado ao dimensionamento estrutural obedecendo todas as normas pertinentes, além de realizar todo o detalhamento, planos de fabricação e montagem e quantitativos necessários à execução da obra. $\mathrm{O}$ dimensionamento da estrutura aponta-se como algo complexo sendo necessário muita prudência principalmente nas verificações das ligações, pois são em grande parte as maiores responsáveis pelo colapso de estruturas de aço, e ocorrem sem aviso.

Palavras-chave: Dimensionamento estrutural; Estrutura de aço; Perfis formado a frio; Perfis laminado a quente.

\begin{abstract}
In Brazil, one of the most used materials in civil construction is steel, because it has a number of advantages such as: high strength; high ductility; high degree of reliability; smaller and more organized construction site; great ease of reinforcement and expansion; speed of execution. Most steel constructions are horizontal, single-story structures. The sheds make up a large part of this portion, with more versatile and economical solutions that provide large free spans, with a high degree of responsibility, which requires special attention and is essential to be performed by qualified professionals. In view of the demand for qualified professionals and the great growth of the use of steel as a structural system in civil construction, this paper seeks to offer a design guide for the steel structure of a typical shed in the region of Caruaru - PE, which uses cold formed profiles (CFP) in the roof system and hot rolled profiles for the pillars. The SAP2000 software will be used for the modeling and structural analysis of the shed, promoting the appropriate procedure for the structural dimensioning obeying all the pertinent norms, besides doing all the detailing, manufacturing and assembly plans and quantities necessary for the execution of the work. The dimensioning of the structure is pointed out as something complex, being necessary a lot of prudence mainly in the verifications of the connections, because they are largely responsible for the collapse of steel structures, and occur without warning.
\end{abstract}

Keywords: Structural design; Steel structure; Cold formed profiles; Hot formed profiles. 


\begin{abstract}
Resumen
En Brasil, uno de los materiales más utilizados en la construcción civil es el acero, porque tiene una serie de ventajas como: alta resistencia; alta ductilidad; alto grado de fiabilidad; obra más pequeña y organizada; facilidad de refuerzo y ampliación; rapidez de ejecución. La mayoría de las construcciones de acero son estructuras horizontales, con una sola planta. Los cobertizos constituyen gran parte de esta parte, con soluciones más versátiles y económicas que proporcionan grandes luces libres, con un alto grado de responsabilidad, que requiere una atención especial y siendo imprescindible que sea realizada por profesionales cualificados. Ante la demanda de profesionales cualificados y el gran crecimiento del uso del acero como sistema estructural en la construcción civil, este trabajo pretende ofrecer una guía de diseño de la estructura de acero de un cobertizo típico en la región de Caruaru - PE, que utiliza perfiles conformados en frío (PCF) en el sistema de cubierta y perfiles laminados en caliente para los pilares. El software SAP2000 se utilizará para el modelado y el análisis estructural del cobertizo, promoviendo el procedimiento adecuado para el diseño estructural de acuerdo con todas las normas pertinentes, además de realizar todos los planos de detalle, fabricación y montaje y las cantidades necesarias para la ejecución de la obra. El dimensionamiento de la estructura se apunta como algo complejo siendo necesaria mucha prudencia sobre todo en las comprobaciones de las conexiones, ya que son las responsables en gran medida del colapso de las estructuras de acero, y se producen sin previo aviso.
\end{abstract}

Palabras clave: Dimensionamiento estructural; Estructura de acero; Perfiles conformados en frío; Perfiles formados en caliente.

\title{
1. Introdução
}

Os galpões ou edifícios industriais são construções comumente em aço ou em concreto pré-moldado, geralmente de um único pavimento, constituídos de sistemas estruturais compostos por pórticos regularmente espaçados, com cobertura superior apoiada em sistemas de terças e vigas ou treliças (tesouras), com grandes áreas cobertas e destinadas para uso comercial (lojas, estacionamentos, centros de distribuição, entre outros), uso industrial, agrícola ou outras aplicações.

Segundo Fakury et al. (2016), a escolha do aço como material estrutural apresenta uma série de vantagens como: elevada resistência, proporcionando seções com dimensões menores; elevada ductibilidade; alto grau de confiança, pois o aço utilizado em obra é industrializado, fabricado em ambiente controlado; canteiro de obras menor e mais organizado - a ausência de manuseio de materiais diferentes reduz a área necessária para o canteiro; apresenta grande facilidade de reforço e ampliação; rapidez de execução, por ser compostas de peças pré-fabricadas com dimensões precisas. Entretanto, devem-se ter cuidados extras na sua utilização para que se evite situações indesejáveis (Fakury et al., 2016). Deve-se reduzir os processos de corrosão, o qual reduz gradualmente a espessura das seções transversais dos elementos, diminuindo sua resistência podendo ser protegido através de pintura ou galvanização (ou outros processos mais especializados). Em situações de incêndio, as principais propriedades mecânicas do aço são negativamente afetadas pela alta temperatura, sendo um risco que deve ser considerado. A proteção contra incêndio pode ser realizada através do uso de revestimentos próprios contra fogo e pela concepção (posicionamento) adequada dos elementos da estrutura.

As estruturas em aço são extremamente vantajosas para obras horizontais como condomínios logísticos, centros de distribuição e obras industriais, pois possibilitam grandes vãos livres, eliminando pilares no interior do galpão que possam dificultar a operação, assim como sua compatibilidade com outros materiais, racionalização dos materiais e mão de obra, grande precisão construtiva, alívio das cargas geradas nas fundações, precisão no orçamento, reciclabilidade e preservação do meio ambiente (CBCA, 2020), e menor prazo de execução quando comparado com outros materiais (Bellei, Pinhp, \& Pinho, 2008).

Além da otimização do espaço, o sistema estrutural em aço para este tipo de empreendimento pode resultar, segundo a MEDABIL (2020), em uma redução de cerca de $30 \%$ nos custos se comparada às estruturas convencionais. Além do custo e do prazo de execução, esse sistema apresenta grande facilidade quanto a necessidade de ampliação. No entanto, para que tais vantagens sejam plenamente usufruídas, é indispensável ter um projeto estrutural em aço elaborado por engenheiros capacitados, pois se requer atenção especial sobre o aço quando comparado a outros tipos de sistemas construtivos, além da necessidade de manutenções periódicas.

Segundo a revista Arquitetura e Aço (2015), a construção em aço no Brasil cresceu ao ritmo de $11 \%$ ao ano entre 2002 
e 2012, tendo em vista a realidade de mercado e a demanda por profissionais capacitados. Dessa forma, este trabalho cujo tema explora uma área de elevada importância na engenharia estrutural, justifica-se na intenção de nutrir o mercado da construção civil, para que mais engenheiros possam desenvolver projetos com qualidade, economia e segurança, através de um roteiro de projeto de um galpão, um dos tipos de construção mais comuns em aço.

Assim, este projeto utiliza o fato de que os galpões são estruturas altamente competitivas na região, pois os perfis formados a frio (chapa dobrada) são bastante utilizados como estrutura de cobertura. Entretanto, tais estruturas normalmente são feitas de maneira inadequada, uma vez que, muitos são feitas de forma irregular sem qualquer rigor técnico, devido, dentre outros motivos, a não elaboração de projetos estruturais feitos por engenheiros especializados em estruturas de aço, que se encontrem na região da cidade de Caruaru.

Neste contexto, este trabalho apresentará um roteiro de dimensionamento de um galpão típico em estrutura de aço a ser construído na região da cidade de Caruaru-PE, na qual: para os pilares serão utilizados perfis laminados a quente; a fundação será em sapatas de concreto armado; na coberta serão utilizados perfis formados a frio (chapa dobrada), pois são cada vez mais viáveis para uso na construção civil e, no trabalho de Pillar (2013), vê-se que esse tipo de perfil proporciona maior flexibilidade para formatos diferentes de cobertura, além de ser mais leve e mais econômico, nessa situação de projeto, que o perfil laminado a quente. Os principais objetivos da pesquisa são:

1. Selecionar/dimensionar os seguintes elementos de fechamento (de forma a garantir segurança estanqueidade e confortos térmico e acústico): telhas, painéis de fechamento vertical, calhas, platibandas etc.;

2. Realizar a concepção estrutural da estrutura de um galpão;

3. Determinar as ações tendo como base as normas ABNT NBR 6120:2019, ABNT NBR 6123:1988 e ABNT NBR 8681:2003;

4. Efetuar o pré-dimensionamento dos elementos que compõem a estrutura, como terças, pilares, vigas e travessas de fechamento;

5. Realizar a modelagem, análise e o dimensionamento da estrutura utilizando o software SAP2000;

6. Realizar a seleção/verificação dos elementos do treliçado, das terças, das barras de contraventos, das vigas e travessas de fechamento, também correntes ou agulhas (barras de travamento lateral das terças) e dos pilares utilizando um roteiro de cálculo em conformidade com as normas ABNT NBR 8800:2008 e ABNT NBR 14762:2010;

7. Realizar a seleção/verificação dos elementos utilizados nas ligações: parafusos, soldas e chumbadores (meios de ligação); e chapas de ligação, suportes de fixação das terças, placa de base etc. (elementos de ligação);

8. Elaborar o detalhamento do projeto, bem como o quantitativo de material a ser utilizado.

\section{Metodologia}

A pesquisa refere-se a uma metodologia com abordagem quali-quantitativa entendida como uma classe de investigação caracterizada pelo entendimento mais aprofundado da realidade (Malhotra, Rocha, \& Laudisio, 2005), com o propósito de desenvolver teorias fundamentadas (Flick, 2009), e é caracterizada pelos dados numéricos, com medições de grandezas no qual, tem-se números com respectivas unidades, gerando dados que podem ser tratados matematicamente (Pereira et al., 2018).

Nesta seção serão apresentadas as características iniciais do projeto, como a descrição da edificação, o lançamento da estrutura, os materiais utilizados, assim como a determinação das ações atuantes no galpão e as combinações relacionadas aos estados limites analisados. Abaixo segue o fluxograma das etapas que devem ser cumpridas na elaboração do projeto (Figura 1). 
Figura 1 - Fluxograma do projeto.



Fonte: Autores (2021).

\subsection{Descrição do galpão}

Neste trabalho, trata-se de um galpão industrial fictício a ser localizado na zona industrial e logística de Caruaru - PE, no bairro do Alto do Moura (pin azul - Figura 2). O galpão, com telhado em duas águas, possui comprimento de $58 \mathrm{~m}$, largura de $26 \mathrm{~m}$ e altura de pé direito de $8 \mathrm{~m}$ e portão centrado com dimensões 5 x $5 \mathrm{~m}$, conforme é apresentado nas Figuras 3 A e B.

Figura 2 - Localização via satélite do galpão.

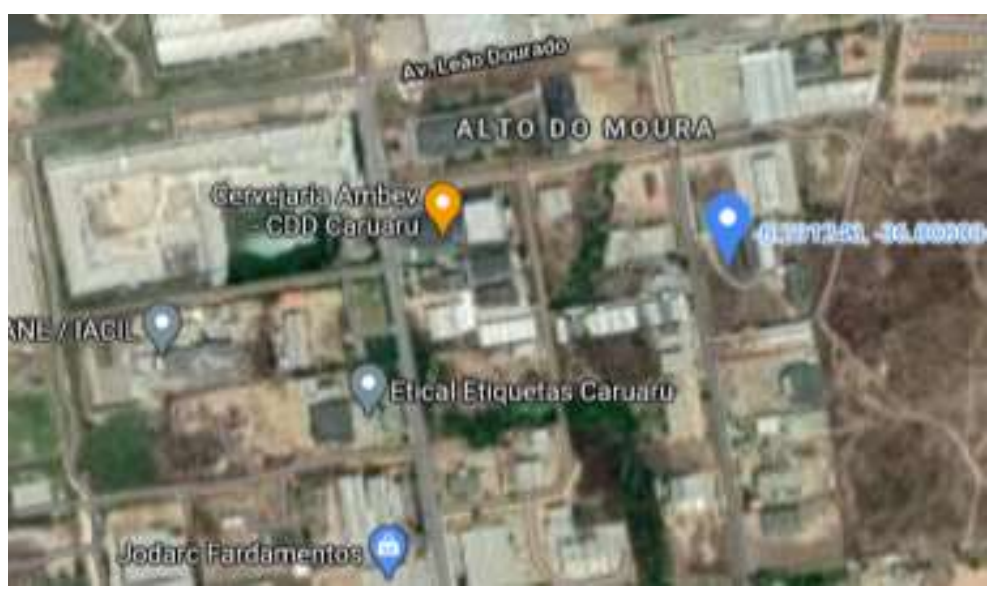

Fonte: Google Maps (2021).

Figura 3 - (a) Vista superior do galpão; (b) Visão frontal galpão (dimensões em m).

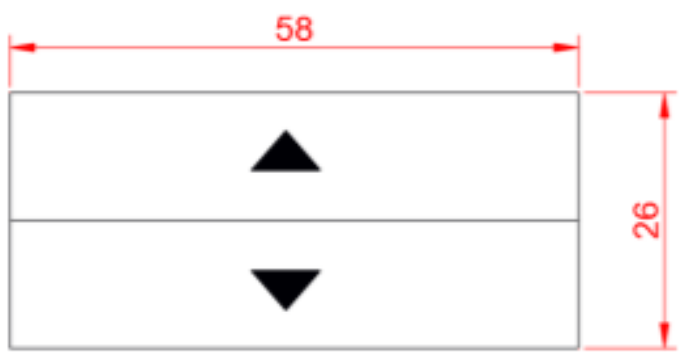

(a)

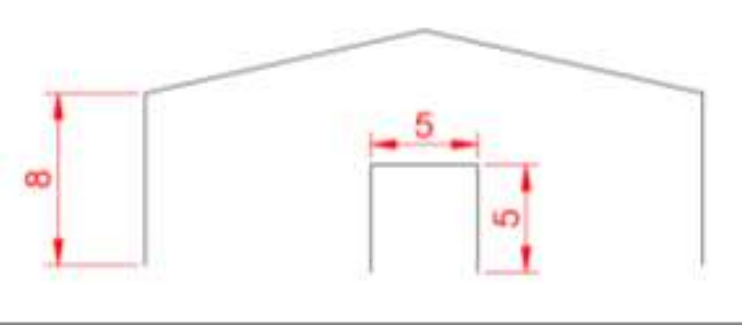

(b)

Fonte: Autores (2021).

\subsection{Materiais utilizados}

Para a cobertura utilizadas telhas termoacústicas ISOTELHA® PUR tipo aço-aço com $30 \mathrm{~mm}$ de espessura de material isolante, seguindo catálogo da ISOESTE. Esta deve ter inclinação mínima de $6 \%$, então optou-se por adotar a inclinação de 
$10 \%$ e para o fechamento foi utilizado alvenaria. Os demais elementos utilizados estão especificados na Tabela 1 abaixo.

Tabela 1 - Parâmetros necessários para cálculo da ação de vento.

\begin{tabular}{ccc}
\hline Materiais & Especificação & Onde se utiliza \\
\hline Perfis Laminados & MR-250 & Vigas, Pilares, \\
contraventamentos & Ligações \\
Perfis formados a frio & MR-250 & Terças, elementos da treliça \\
Eletrodo & AWS E-7018 & Ligações \\
Parafusos e porcas & ASTM A-325 & Ligações \\
Concreto e graute & $25 \mathrm{MPa}$ & Fundação \\
\hline
\end{tabular}

Fonte: Autores (2021).

\subsection{Lançamento da estrutura}

$\mathrm{Na}$ fase de lançamento da estrutura, que consiste no posicionamento adequado dos elementos estruturais, deve-se atender as seguintes considerações (Xerez Neto; Cunha, 2020):

1. A distância entre as terças é determinada pelo vão admissível das telhas, conforme recomendação do fabricante (KINGSPAN ISOESTE, 2020). Geralmente o vão está entre 1,50 m e 2,00 m;

2. Para as terças, com perfis formado a frio, é recomendado um vão máximo de 7,0 m;

3. As diagonais da treliça devem estar direcionadas de modo que trabalhem predominantemente à tração, pois se tem o maior aproveitamento das seções utilizadas, e com ângulo entre as diagonais e o banzo horizontal entre $30^{\circ}$ e $60^{\circ}$;

4. Para o fechamento vertical será utilizado alvenaria, o qual é necessário a utilização de vigas de apoio, se utiliza perfil I laminado;

5. O contraventamento no plano da cobertura está disposto em $\mathrm{X}$, e deve ser pensado de forma que garanta o adequado travamento das barras comprimidas e, também, a adequada transmissão das cargas horizontais do vento para os apoios da estrutura. Empiricamente, a distância entre os planos de contraventamento não deve ultrapassar $20 \mathrm{~m}$. Adicionalmente, para transmissão das forças de vento, são previstos contraventamentos nas bordas da cobertura;

6. O contraventamento vertical é efetuado para dar maior estabilidade global da estrutura. Usualmente, a cada 3 painéis, entre tesouras, deve-se ter um contraventamento em X;

7. À medida que vai se afastando do centro da treliça, os esforços solicitantes nas diagonais e nos montantes aumentam, sendo assim, é importante diminuir o espaçamento entre os montantes do centro para extremidade.

Tendo em vista todos esses critérios, foi efetuado o lançamento da estrutura (Figuras 4 a 7). 
Figura 4 - Planta de Locação (dimensões em mm).

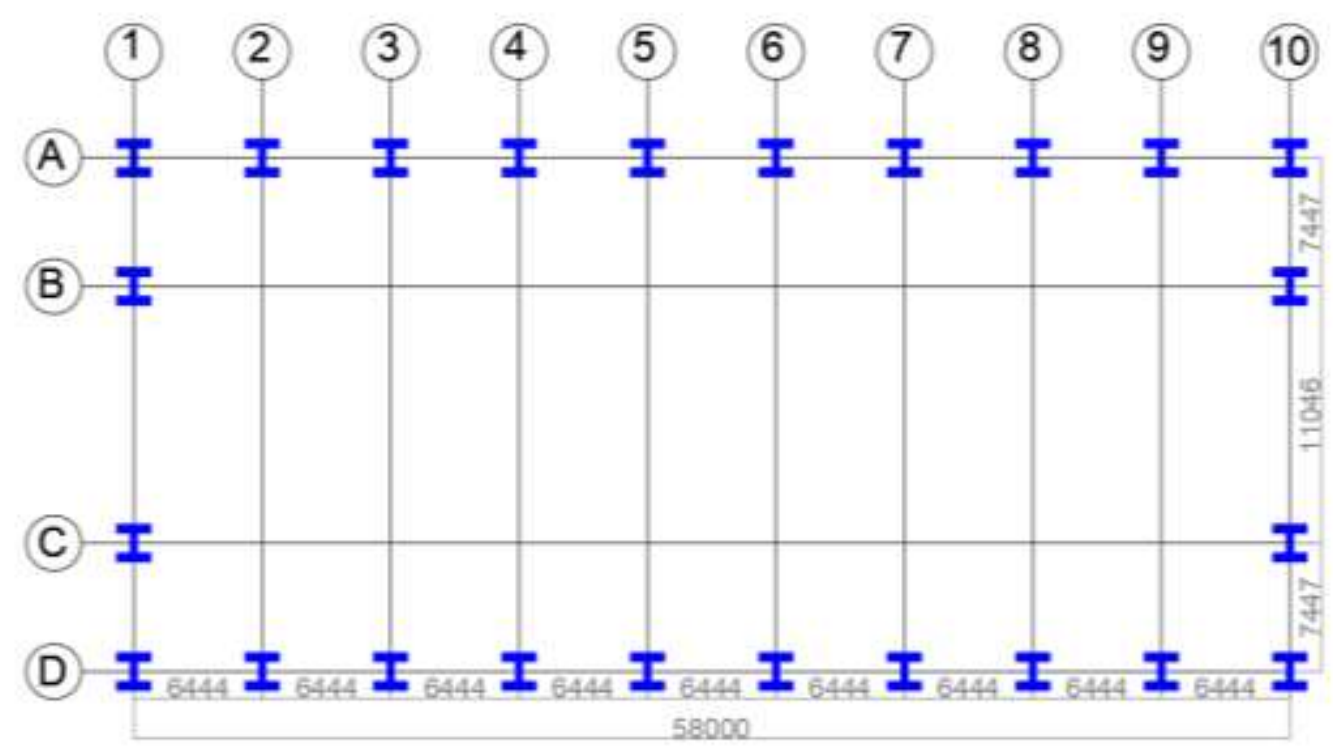

Fonte: Autores (2021).

Figura 5 - Lançamento de metade da treliça referente aos eixos 1 a 10 (dimensões em mm).

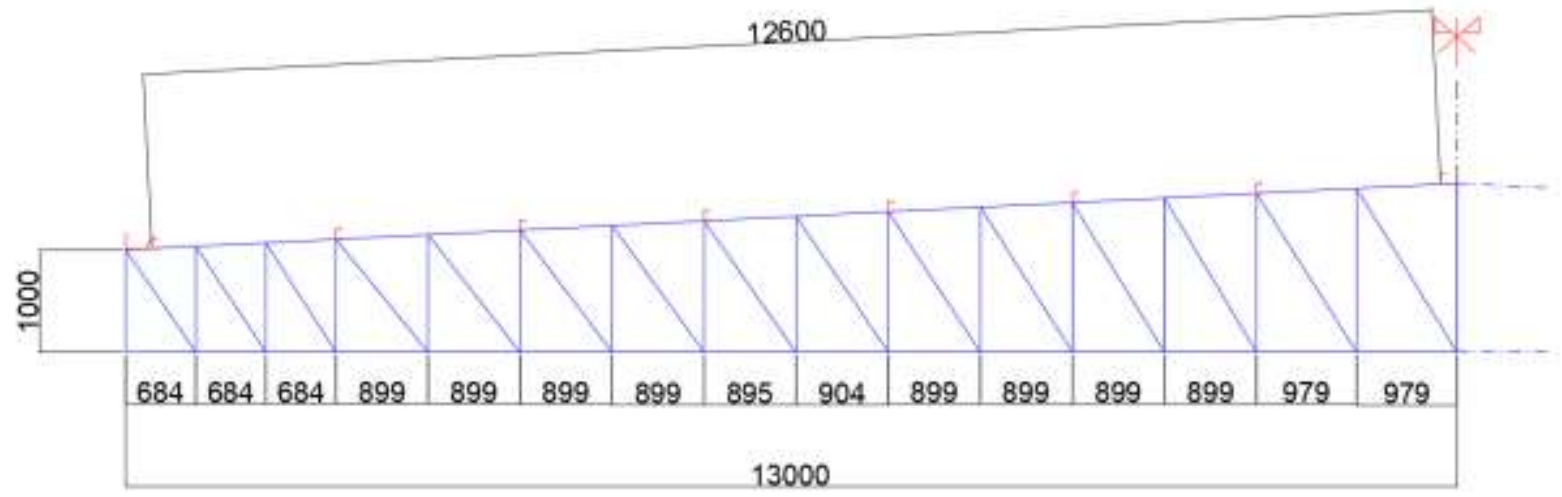

Fonte: Autores (2021).

Figura 6 - Eixos A e D (dimensões em mm).

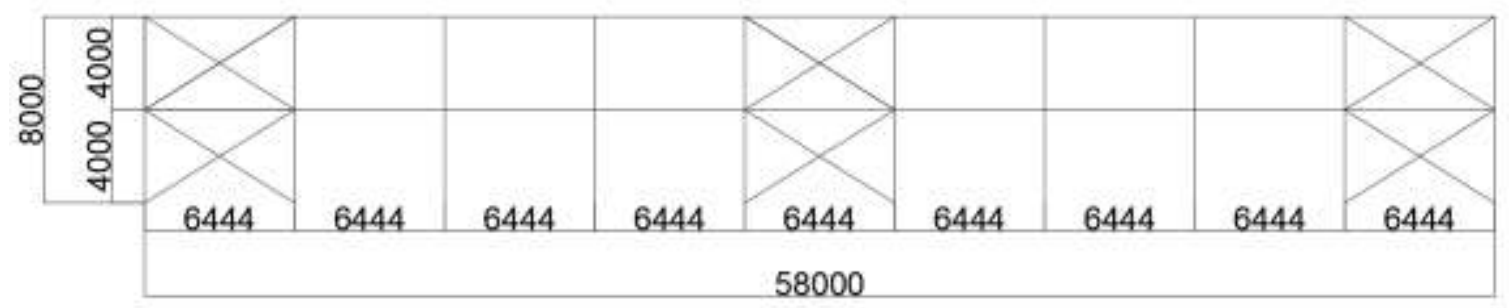

Fonte: Autores (2021). 




Fonte: Autores (2021).

\subsection{Ações}

No dimensionamento da estrutura, deve-se prever quais ações estarão atuando na estrutura. A seguir são apresentadas as ações consideradas no dimensionamento do galpão.

\subsubsection{Ações permanentes}

É formada pelo peso próprio dos elementos, pode ser obtido no catálogo dos fabricantes, tanto para os perfis de aço, quanto para a telha. No caso dos perfis de aço, pode-se também consultar a massa específica do aço na ABNT NBR 8800:2008 e na ABNT NBR 14762:2010, cujo valor é de $7850 \mathrm{~kg} \cdot \mathrm{m}^{-3}$.

\subsubsection{Ações variáveis}

São ações que ocorrem com variação significativa ao longo da vida da construção. Nesse projeto são considerados os seguintes carregamentos atuantes na cobertura:

a) Sobrecarga na cobertura

Seguindo o anexo B da ABNT NBR 8800:2008, nas coberturas comuns, na ausência de especificação mais rigorosa admite-se uma sobrecarga característica mínima de $0,25 \mathrm{kN} \cdot \mathrm{m}^{-2}$, em projeção horizontal. Essa sobrecarga engloba as cargas decorrentes de instalações elétricas e hidráulicas, de isolamento térmico e acústico ficadas na cobertura, até um limite superior de $0,05 \mathrm{kN} \cdot \mathrm{m}^{-2}$. Na ABNT NBR 6120:2019 é mencionada a verificação em relação ao fenômeno do empoçamento progressivo, no entanto, para coberturas com inclinações maiores que $5 \%$, não é necessário a realização dessa verificação. Também, todo elemento isolado de cobertura deve ser projetado para suportar, na posição mais desfavorável, uma carga concentrada de $1 \mathrm{kN}$, além do carregamento permanente. Essa carga concentrada deve ser considerada atuando isolada das demais forças variáveis. 
b) Forças devido ao vento

A ação do vento deve ser calculada de acordo com a ABNT NBR 6123:1988. Resumidamente, as informações necessárias para o cálculo estão apresentadas na Tabela 2 abaixo e podem ser encontradas no item 5 da norma.

Tabela 2 - Parâmetros necessários para cálculo da ação de vento.

\begin{tabular}{cccc}
\hline Velocidade Básica (V0) & S1 & S2 & S3 \\
\hline $30 \mathrm{~m} / \mathrm{s}$ & 1 & 0.832 & 1 \\
\hline
\end{tabular}

Fonte: Autores (2021).

Os coeficientes de forma são obtidos no item 6 da ABNT NBR 6123:1988, especificamente, nas Tabelas 4 e 5 da norma. $\mathrm{O}$ galpão avaliado neste projeto enquadra-se na relação $\mathrm{h} / \mathrm{b}<1 / 2$ e $2<\mathrm{a} / \mathrm{b}<4$; portanto, os coeficientes de forma externo no entorno da edificação é dado conforme a Figuras 8:

Figura 8 - Coeficiente de forma externo no galpão.


Fonte: Autores (2021).

Os coeficientes de forma interno dependem da permeabilidade da edificação, a ABNT NBR 6123:1988 afirma que "são considerados impermeáveis os seguintes elementos construtivos e vedações: lajes e cortinas de concreto armado ou protendido; paredes de alvenaria, de pedra, de tijolos, de blocos de concreto e afins, sem portas, janelas ou quaisquer outras aberturas [...]", ou seja, para este trabalho seria considerado impermeável, entretanto, de forma a reduzir os efeitos da ação do vento que surgiriam pela presença do portão (abertura dominante), numa pior hipótese, poderiam aumentar em até $80 \%$ os esforços solicitantes, sendo necessário uma estrutura mais robusta pra combater esses efeitos. Então, como recurso estratégico serão utilizadas aberturas fixas como venezianas, lanternins ou cobogós, com o intuito de tornar permeável todas as faces do galpão e reduzir os esforços devido ao vento, para esse caso o coeficiente de forma interno Ci é igual a $-0,3$ ou 0 , o mais nocivo entre os dois.

No lançamento das cargas de ação vento foi considerado 3 grupos de situações que possam ocorrer, no primeiro grupo, as cargas de ação do vento atuam na estrutura como todo (telhado e pilares), no segundo grupo foi modelado a estrutura completa do galpão considerando a ação do vento apenas no telhado sem considerar a pressão nas paredes (uma vez que, isso é possível de ocorrer a depender no nível de obstrução que se tem ao redor do galpão), pois o efeito da sucção nos pilares (ação de dentro pra fora) gera flecha pra baixo na treliça, que é contrária a flecha da ação de sucção na tesoura, e vice-versa. Assim, teremos os casos críticos de tração e compressão em cada banzo. E o terceiro caso, ação do vento atuando somente nos pilares, considerando os três casos críticos possíveis de solicitação que possam surgir nos elementos estruturais.

Devido à alvenaria, a influência da ação do vento nas paredes foi distribuída entre os pilares e as vigas que fecham o painel pelo método do quinhão de cargas. 


\subsection{Combinações}

De acordo com a ABNT NBR 8681:2003, para a verificação da segurança em relação aos estados limites, para cada tipo de carregamento devem ser consideras as combinações de ações que acarretam os efeitos mais desfavoráveis nas seções críticas da estrutura. As normas referentes as estruturas de aço ABNT NBR 8800:2008 e ABNT NBR 14762:2010 apresentam os coeficientes de ações para ser utilizado no dimensionamento.

As ações permanentes calculadas no estado-limite último, o coeficiente de ponderação para a situação desfavorável para peso próprio de estruturas metálicas é igual a 1,25, na combinação normal. Já as ações variáveis foram consideradas independentes e agrupadas. Também são considerados os fatores de combinação e de redução para as ações variáveis no cálculo das combinações, conforme especificados nas normas ABNT NBR 8800:2008 e ABNT NBR 14762:2010.

\subsubsection{Combinações do estado-limite último}

As combinações de ações para o estado-limite último estão apresentadas na Tabela 3. Observa-se na tabela a consideração de combinações nas quais somente uma das cargas variáveis está atuando, e também são consideradas combinações quando ocorrem simultaneamente. Quando simultâneas, deve ser feita a verificação de qual seria a carga principal. Outro detalhe importante está no fato de que se deve verificar para qual coeficiente de pressão interno se tem as maiores solicitações. Lembrando que, apesar de não estar explícito na Tabela 3, o coeficiente de pressão interno relativo à situação da abertura dominante do portão deve ser considerado.

Tabela 3 - Combinações estado-limite último.

\begin{tabular}{ccc}
\hline COMBINAÇÃO & TIPO & AÇÕES COM PONDERAÇÕES \\
\hline 1 & Normal & $1,25 \mathrm{G}_{\text {perm }}+1,50 \mathrm{Q}_{\mathrm{sc}}$ \\
2 & Normal & $1,25 \mathrm{G}_{\text {perm }}+1,40$ Vento $0^{\circ}(\mathrm{Ci}=-0,3$ ou 0,0$)$ \\
3 & Normal & $1,25 \mathrm{G}_{\text {perm }}+1,40$ Vento $90^{\circ}(\mathrm{Ci}=-0,3$ ou 0,0$)$ \\
4 & Normal & $1,25 \mathrm{G}_{\text {perm }}+1,50 \mathrm{Q}_{\text {sc }}+1,40^{*} 0,60$ Vento $0^{\circ}(\mathrm{Ci}=-0,3$ ou 0,0$)$ \\
5 & Normal & $1,25 \mathrm{G}_{\text {perm }}+1,50 \mathrm{Q}_{\text {sc }}+1,40^{*} 0,60$ Vento $90^{\circ}(\mathrm{Ci}=-0,3$ ou 0,0$)$ \\
6 & Normal & $1,25 \mathrm{G}_{\text {perm }}+1,40$ Vento $0^{\circ}(\mathrm{Ci}=-0,3$ ou 0,0$)+1,50^{*} 0,70 \mathrm{Q}_{\text {sc }}$ \\
7 & Normal & $1,25 \mathrm{G}_{\text {perm }}+1,40$ Vento $90^{\circ}(\mathrm{Ci}=-0,3$ ou 0,0$)+1,50 * 0,70 \mathrm{Q}_{\mathrm{sc}}$ \\
8 & Normal & $1,0 \mathrm{G}_{\text {perm }}+1,4$ Vento $0^{\circ}(\mathrm{Ci}=-0,3$ ou 0,0$)$ \\
9 & Normal & $1,0 \mathrm{G}_{\text {perm }}+1,4$ Vento $90^{\circ}(\mathrm{Ci}=-0,3$ ou 0,0$)$ \\
\hline
\end{tabular}

Fonte: Autores (2021).

sendo: $\mathrm{G}_{\text {perm }}$ relativo às ações permanentes agrupadas; e $\mathrm{Q}_{\mathrm{sc}}$ à sobrecarga na cobertura. "Vento 0" é o vento incidente perpendicular na face de menor dimensão horizontal e "Vento $90^{\circ}$ " o vento incidente perpendicular à face de maior dimensão horizontal.

\subsubsection{Combinações do estado-limite de serviço}

As combinações de ações para o estado-limite de serviço estão apresentadas na Tabela 4. No caso do galpão, é necessário a verificação de deslocamentos excessivos, na qual se utiliza a combinação quase permanente e também, de acordo com o Anexo A da ABNT NBR 14762:2010, deve-se considerar combinações raras de serviço. Utilizam-se as ações variáveis de mesmo sentido que o da ação permanente e consideram-se também apenas as ações variáveis de sentido oposto ao da ação permanente (vento de sucção) com seu valor característico. 
Tabela 4 - Combinações estado-limite de serviço.

\begin{tabular}{ccc}
\hline COMBINAÇÃO & TIPO & AÇÕES COM PONDERAÇÕES \\
\hline 10 & Quase permanente & $1,0 \mathrm{G}_{\text {perm }}+0,4 \mathrm{Q}_{\mathrm{sc}}$ \\
11 & Rara & $1,0 \mathrm{G}_{\text {perm }}+1,0 \mathrm{Q}_{\mathrm{sc}}+0,3$ Vento $0^{\circ}(\mathrm{Ci}=-0,3$ ou 0,0$)$ \\
12 & Rara & $1,0 \mathrm{G}_{\text {perm }}+1,0 \mathrm{Q}_{\mathrm{sc}}+0,3$ Vento $90^{\circ}(\mathrm{Ci}=-0,3$ ou 0,0$)$ \\
13 & Rara & $1,0 \mathrm{G}_{\text {perm }}+1,0$ Vento $0^{\circ}+0,6 \mathrm{Q}_{\mathrm{sc}}(\mathrm{Ci}=-0,3$ ou 0,0$)$ \\
14 & Rara & $1,0 \mathrm{G}_{\text {perm }}+1,0$ Vento $90^{\circ}+0,6 \mathrm{Q}_{\mathrm{sc}}(\mathrm{Ci}=-0,3$ ou 0,0$)$ \\
15 & - & 1,0 Vento $0^{\circ}(\mathrm{Ci}=-0,3$ ou 0,0$)$ \\
16 & - & 1,0 Vento $90^{\circ}(\mathrm{Ci}=-0,3$ ou 0,0$)$ \\
\hline
\end{tabular}

Fonte: Autores (2021).

sendo: $G_{\text {perm }}$ relativo às ações permanentes agrupadas e $Q_{\text {sc }}$ à sobrecarga na cobertura.

\subsection{SAP2000}

O software utilizado na análise da estrutura foi o SAP2000 que é um programa de elementos finitos, preparado para realizar, de forma totalmente integrada, a modelagem, análise e dimensionamento de vários problemas de engenharia (Figura 9).

Figura 9 - Fluxograma referente as etapas no SAP2000.

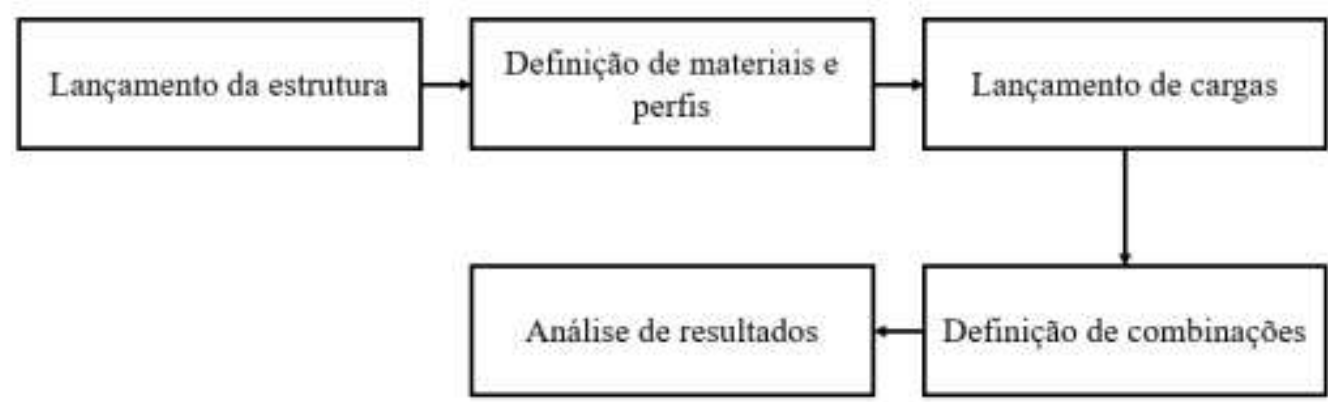

Fonte: Autores (2021).

\section{Resultados e Discussão}

Nesta seção serão apresentadas as solicitações e as verificações dos elementos estruturais do galpão, e também são apresentadas as ligações entre os elementos que compõem a estrutura e os quantitativos necessários para execução.

\subsection{Treliça}

\subsubsection{Estado-limite último}

Para o dimensionamento da treliça foi utilizado tabelas de propriedades disponíveis no catálogo dos fabricantes de perfis formado a frio (GRAVIA, 2013). Como os banzos superior e inferior estão submetidos a maior solicitação, utilizou-se um perfil composto por dois perfis UDC simples (U 150 x 50 x 4,75), para que não fosse necessário elevar muito o peso total da treliça para atender a compressão no banzo superior, a solidarização (travejamento) do perfil é efetuado através de presilhas (chapas separadoras). Para as diagonais e montantes foi adotado perfis UDC simples (U 100 x 50 x 4,75).

Sendo a treliça ideal um elemento submetido somente a cargas axiais, a união entre banzos diagonais e montantes é realizado através de chapas Gousset ou chapa de nó (Figura 10) soldadas entre eles para que não exista excentricidade entre as linhas dos centroides (ponto de trabalho) e não necessite considerar a flexão nos elementos. 
Os elementos tracionados devem ser verificados de acordo como item 9.6 da ABNT NBR 14762:2010, os elementos comprimidos de acordo com o item 9.7 da mesma norma.

Figura 10 - Detalhe de ligação entre os elementos da treliça.

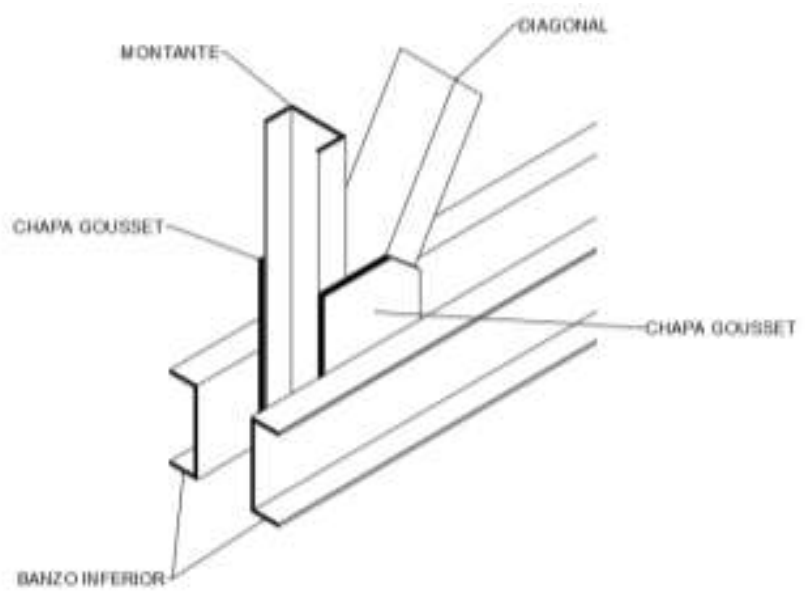

Fonte: Autores (2021).

No banzo superior, entretanto, é inevitável desconsiderar a flexão, já que existem terças que não estão posicionadas nos nós da treliça (terças de cumeeira e terça de apoio as calhas - Figura 5). A verificação para a flexão composta deve seguir o item 9.9 da ABNT NBR 14762:2010

Na Tabela 5 abaixo se encontra um resumo das solicitações de cálculo máximas e o aproveitamento dos elementos quanto à solicitação.

Tabela 5 - Solicitação de cargas na treliça.

\begin{tabular}{cccc}
\hline ELEMENTO & Nd (kN) & Md (kN·m) & APROVEITAMENTO (\%) \\
\hline Banzo superior (Compressão) & 173,799 & 0,7387 & 46,7 \\
Banzo inferior (Tração) & 167,654 & - & 31,9 \\
Banzo superior (Tração) & 64,813 & 0,5494 & 14,8 \\
Banzo inferior (Compressão) & 110,343 & - & 27,5 \\
Montante (Tração) & 30,795 & - & 22,9 \\
Diagonal (Tração) & 75,959 & - & 56,4 \\
Montante (Compressão) & 41,166 & - & 71,3 \\
Diagonal (Compressão) & 32,635 & - & 78,2 \\
\hline
\end{tabular}

Fonte: Autores (2021).

\subsubsection{Estado-limite de serviço}

As verificações para estado-limite de serviço neste tópico estão relacionadas aos deslocamentos máximos que seguem os limites estabelecidos no anexo A da ABNT NBR 14762:2010. O limite definido pela norma para as treliças é de L/180 considerando as combinações raras de serviço e de L/120 considerando apenas as ações variáveis de sentido oposto ao da ação permanente, no qual L é o vão da treliça. Sendo assim, o limite de deslocamento é igual a 14,4 cm e $21,7 \mathrm{~cm}$ respectivamente. Dessa forma os respectivos valores obtidos no SAP2000 foram de 2,6 cm para o primeiro caso e de 1,9 $\mathrm{cm}$ para o segundo. 


\subsection{Terças}

\subsubsection{Estado-limite último}

Devido a inclinação do perfil, as terças trabalham sob flexão oblíqua, além da compressão devido a incidência de vento na parede frontal. O perfil adotado foi do tipo UDC enrijecido (UDC 200 x 75 x 25 x 3).

A redução do comprimento de flambagem no eixo de menor inércia é feita através de cantoneira (L 25,4 x 3,17) posicionadas nos terços da treliça (Figura 11).

Figura 11 - Fixação das correntes na terça.



Fonte: Autores (2021).

Na Tabela 6, se encontra as solicitações de cálculo para as terças. A verificação para a flexão composta deve seguir o item 9.9 da ABNT NBR 14762:2010.

Tabela 6 - Solicitação de cargas na terça.

\begin{tabular}{ccccccc}
\hline ELEMENTO & $\mathbf{N}_{\mathbf{d}}(\mathbf{k N})$ & $\left.\mathbf{M}_{\mathbf{x d}} \mathbf{( k N} \cdot \mathbf{m}\right)$ & $\mathbf{M}_{\mathbf{y d}} \mathbf{( k N \cdot m )}$ & $\mathbf{V}_{\mathbf{x d}}(\mathbf{k N})$ & $\mathbf{V}_{\mathbf{y d}}(\mathbf{k N})$ & APROVEITAMENTO $(\%)$ \\
\hline Terça & 13,539 & 5,281 & 0,412 & 0,275 & 3,284 & 61,1 \\
\hline
\end{tabular}

Fonte: Autores (2021).

\subsubsection{Estado-limite de serviço}

As verificações para estado-limite de serviço neste tópico estão relacionadas aos deslocamentos máximos que seguem os limites estabelecidos no anexo A da ABNT NBR 14762:2010. O limite definido pela norma para as terças de cobertura é de L/180 considerando as combinações raras de serviço e de L/120 considerando apenas as ações variáveis de sentido oposto ao da ação permanente, no qual L é o vão da terça. Sendo assim, o limite de deslocamento é igual a $35,8 \mathrm{~mm}$ e $53,7 \mathrm{~mm}$ respectivamente. Dessa forma os respectivos valores obtidos no SAP2000 foram de 34,6 mm para o primeiro caso e de $29,7 \mathrm{~mm}$ para o segundo.

\subsection{Vigas}

\subsubsection{Estado-limite último}

Da mesma forma que a terça, as vigas estão sob flexão oblíqua, isto se deve ao fato de a ação do vento ter sido distribuída pelo quinhão de cargas como mencionado no item 2.4.2. A compressão nas vigas surge devido aos esforços laterais no pilar.

A verificação para o estado-limite último, segue conforme o item 5.5.1 da ABNT NBR 8800:2008. 
Por simplificação adotou-se um único perfil para todas as vigas (Figura 12), e para que o perfil cumpra o requisito de esbeltez limite, por estar submetido a compressão, se utilizou um perfil H (W 200 x 35,9 (H)). Prefere-se utilizar os dois ou os três primeiros perfis do catálogo dos fabricantes (GERDAU, 2020), pois são de uso mais comum e mais provável de se ter em estoque.

Figura 12 - Lançamento de vigas e pilares (dimensões em mm).



Fonte: Autores (2021).

Na Tabela 7 se encontra as solicitações para as vigas e o aproveitamento da seção em relação a flexocompressão.

Tabela 7 - Solicitação de cargas na viga.

\begin{tabular}{ccccccc}
\hline ELEMENTO & $\mathbf{N}_{\mathbf{d}}(\mathbf{k N})$ & $\mathbf{M}_{\mathbf{x d}}(\mathbf{k N} \cdot \mathbf{m})$ & $\mathbf{M}_{\mathbf{y d}} \mathbf{( k N \cdot \mathbf { m } )}$ & $\mathbf{V}_{\mathbf{x d}}(\mathbf{k N})$ & $\mathbf{V}_{\mathbf{y d}}(\mathbf{k N})$ & APROVEITAMENTO $(\boldsymbol{\%})$ \\
\hline V1 & 21,428 & 40,002 & 7,125 & 6,444 & 33,911 & 72,7 \\
V2 & 1,826 & 44,891 & 0,8658 & 0,538 & 31,826 & 55,1 \\
V3 & 1,325 & 35,157 & 2,564 & 2,053 & 31,242 & 49,0 \\
V4 & 1,847 & 31,014 & 2,601 & 2,398 & 28,842 & 44,4 \\
V5 & 15,911 & 35,979 & 1,506 & 1,800 & 31,518 & 49,0 \\
V6 & 1,087 & 43,468 & 2,152 & 1,926 & 31,525 & 57,4 \\
V7 & 1,839 & 31,045 & 2,609 & 2,455 & 28,881 & 44,4 \\
V8 & 1,958 & 33,831 & 7,123 & 4,539 & 29,358 & 62,2 \\
V9 & 21,428 & 40,002 & 7,125 & 6,444 & 33,911 & 72,7 \\
V10 & 2,721 & 34,990 & 7,817 & 6,386 & 31,157 & 65,5 \\
V11 & 3,311 & 62,627 & 7,816 & 5,358 & 29,187 & 62,8 \\
V12 & 3,245 & 31,034 & 5,242 & 4,938 & 28,876 & 52,8 \\
V13 & 3,248 & 31,021 & 5,242 & 4,779 & 28,845 & 52,8 \\
V14 & 3,201 & 30,961 & 5,073 & 4,750 & 28,832 & 52,2 \\
V15 & 1,086 & 43,466 & 2,152 & 1,926 & 31,525 & 57,4 \\
V16 & 3,245 & 31,034 & 5,242 & 4,938 & 28,876 & 52,8 \\
V17 & 3,311 & 32,627 & 7,816 & 5,358 & 29,187 & 62,8 \\
V18 & 21,428 & 40,002 & 7,124 & 6,443 & 33,911 & 72,7 \\
V19 & 4,878 & 56,208 & 0,000 & 5,196 & 37,880 & 66,1 \\
V20 & 12,046 & 56,727 & 4,655 & 3,534 & 37,895 & 81,3 \\
V21 & 4,889 & 39,174 & 6,544 & 6,701 & 33,252 & 66,5 \\
V22 & 12,046 & 56,727 & 4,655 & 3,534 & 37,895 & 8 \\
\hline
\end{tabular}

Fonte: Autores (2021). 


\subsubsection{Estado-limite de serviço}

A verificação em relação ao estado-limite de serviço neste tópico se trata dos deslocamentos excessivos que não provoquem danos a outros componentes da construção. O anexo C da ABNT NBR 8800:2008 dita os deslocamentos máximos permitidos. As vigas se enquadram como vigas de piso no qual o limite é igual a L/350, no qual L é o comprimento do vão, ou $15 \mathrm{~mm}$, caso existam alvenaria, que é o caso. Em resumo, o deslocamento limite de $15 \mathrm{~mm}$ é o mais restritivo para todas as vigas. Na Tabela 8 é possível verificar o valor dos deslocamentos obtidos no SAP2000.

Tabela 8 - Flechas calculadas.

\begin{tabular}{lccccccccccc}
\hline ELEMENTO & V1 & V2 & V3 & V4 & V5 & V6 & V7 & V8 & V9 & V10 & V11 \\
\hline $\boldsymbol{\delta}(\mathbf{m m})$ & 7,6 & 4,9 & 5,3 & 5,2 & 5,3 & 5,2 & 5,3 & 4,9 & 7,6 & 7,6 & 4,9 \\
\hline ELEMENTO & V12 & V13 & V14 & V15 & V16 & V17 & V18 & V19 & V20 & V21 & V22 \\
\hline $\boldsymbol{\delta}(\mathbf{m m})$ & 5,3 & 5,2 & 5,3 & 5,2 & 5,3 & 4,9 & 7,6 & 10,5 & 10,5 & 10,5 & 10,5 \\
\hline
\end{tabular}

Fonte: Autores (2021).

\subsection{Pilares}

\subsubsection{Estado-limite último}

As cargas laterais de vento fazem com que os pilares estejam solicitados sob flexocompressão oblíqua cuja verificação para o estado-limite último, segue conforme o item 5.5.1 da ABNT NBR 8800:2008.

Desse modo partiu-se para a escolha de um perfil H, (W 250 x $73(\mathrm{H})$ ), o qual possui boa inércia nas duas direções, além de ter uma altura de perfil maior que a viga para que houvesse o encaixe das vigas que se ligam na alma do pilar.

Na Tabela 9, estão as solicitações de cálculo para os pilares apresentados na Figura 12 e o aproveitamento da seção quanto ao esforço axial e fletor combinados. 
Tabela 9 - Solicitação de cargas nos pilares.

\begin{tabular}{|c|c|c|c|c|c|c|}
\hline ELEMENTO & $\mathbf{N}_{d}(\mathbf{k N})$ & $M_{x d}(k N \cdot m)$ & $M_{y d}(k N \cdot m)$ & $\mathbf{V}_{\mathrm{xd}}(\mathbf{k N})$ & $\mathrm{V}_{\mathrm{yd}}(\mathrm{kN})$ & APROVEITAMENTO $(\%)$ \\
\hline $\mathrm{P} 1$ & 64,921 & 19,772 & 34,943 & 9,805 & 4,195 & 45,2 \\
\hline $\mathrm{P} 2$ & 81,113 & 18,041 & 6,184 & 1,546 & 2,586 & 17,2 \\
\hline P3 & 31,733 & 54,542 & 0,000 & 0,000 & 6,141 & 27,8 \\
\hline $\mathrm{P} 4$ & 34,464 & 58,669 & 0,000 & 0,000 & 6,451 & 29,9 \\
\hline P5 & 40,964 & 14,686 & 42,641 & 10,660 & 2,392 & 49,4 \\
\hline P6 & 40,051 & 63,091 & 0,000 & 0,000 & 7,195 & 32,2 \\
\hline P7 & 34,464 & 58,669 & 0,000 & 0,000 & 6,415 & 29,9 \\
\hline P8 & 31,733 & 54,542 & 0,000 & 0,000 & 6,141 & 27,8 \\
\hline P9 & 15,909 & 7,076 & 39,954 & 9,988 & 0,122 & 42,3 \\
\hline P10 & 77,688 & 37,299 & 16,444 & 3,576 & 8,79 & 36,4 \\
\hline P11 & 34,498 & 25,615 & 29,498 & 4,582 & 8,538 & 41,9 \\
\hline P12 & 14,341 & 30,356 & 14,422 & 2,180 & 10,119 & 29,2 \\
\hline P13 & 58,610 & 40,481 & 29,916 & 0,476 & 10,12 & 50,4 \\
\hline P14 & 58,610 & 40,481 & 29,916 & 0,476 & 10,12 & 50,4 \\
\hline P15 & 63,084 & 21,105 & 34,306 & 9,324 & 4,206 & 45,2 \\
\hline P16 & 38,090 & 33,299 & 1,624 & 0,406 & 6,829 & 19,1 \\
\hline P17 & 20,121 & 40,987 & 0,000 & 0,000 & 0,05 & 20,8 \\
\hline P18 & 43,993 & 42,031 & 0,000 & 0,000 & 8,315 & 22,0 \\
\hline P19 & 40,085 & 14,797 & 42,612 & 10,653 & 2,422 & 49,4 \\
\hline P20 & 48,796 & 40,873 & 0,032 & 0,000 & 8,026 & 21,6 \\
\hline $\mathrm{P} 21$ & 43,993 & 42,031 & 0,000 & 0,000 & 8,315 & 22,0 \\
\hline $\mathrm{P} 22$ & 20,121 & 40,987 & 0,000 & 0,000 & 0,05 & 20,8 \\
\hline $\mathrm{P} 23$ & 15,906 & 7,077 & 39,967 & 9,992 & 0,122 & 42,3 \\
\hline $\mathrm{P} 24$ & 79,446 & 17,974 & 22,587 & 5,647 & 4,600 & 32,8 \\
\hline
\end{tabular}

Fonte: Autores (2021).

\subsubsection{Estado-limite de serviço}

A verificação em relação ao estado-limite de serviço neste tópico se trata dos deslocamentos excessivos que não provoquem danos a outros componentes da construção. O anexo C da ABNT NBR 8800:2008 dita os deslocamentos máximos permitidos. Para os pilares, o limite de deslocamento do topo dos pilares em relação a base é de H/300, no qual H é a altura do pilar. Para os pilares P11, P12, P13, P14, o limite é de 23,3 mm, e para o restante o limite é de 26,7 mm.

Na Tabela 10 é possível verificar o valor dos deslocamentos obtidos no SAP2000.

Tabela 10 - Deslocamentos calculados.

\begin{tabular}{ccccccccccccc}
\hline ELEMENTO & P1 & P2 & P3 & P4 & P5 & P6 & P7 & P8 & P9 & P10 & P11 & P12 \\
\hline $\boldsymbol{\delta}(\mathbf{m m})$ & 10,4 & 1,4 & 0,3 & 0,3 & 0,3 & 0,3 & 0,3 & 0,3 & 1,4 & 10,4 & 1,5 & 1,5 \\
\hline ELEMENTO & P13 & P14 & P15 & P16 & P17 & P18 & P19 & P20 & P21 & P22 & P23 & P24 \\
\hline $\boldsymbol{\delta}(\mathbf{m m})$ & 1,5 & 1,5 & 10,4 & 1,4 & 0,3 & 0,3 & 0,3 & 0,3 & 0,3 & 0,3 & 1,4 & 10,4 \\
\hline \multicolumn{3}{c}{ Fonte: Autores $(2021)}$.
\end{tabular}

\subsection{Contraventamentos verticais e do plano do telhado}

Os elementos do contraventamento tanto os verticais dos eixos A e D quanto os do plano do telhado dão maior estabilidade a estrutura como um todo. Os resultados obtidos no SAP2000 foram gerados a partir de uma análise não-linear para que estes trabalhassem somente a tração. O perfil adotado foi cantoneira de abas iguais L 3.1/2" x 1/4", sendo verificado 
conforme item 5.2 da ABNT NBR 8800:2008. Na Tabela 11 se encontram o esforço axial solicitante de cálculo máximo e o aproveitamento do perfil à tração.

Tabela 11 - Solicitações de cálculo nos contraventamentos.

\begin{tabular}{ccc}
\hline ELEMENTO & $\mathbf{N}_{\mathbf{d}}(\mathbf{k N})$ & APROVEITAMENTO $(\boldsymbol{\%})$ \\
\hline Contraventamento & 24.929 & 11,5 \\
\hline
\end{tabular}

Fonte: Autores (2021).

\subsection{Correntes (ou agulhas)}

Como em torno do eixo de menor inércia as terças apresentam baixa resistência, torna-se necessário diminuir o vão nessa direção. Por isso, faz-se uso de "correntes". As correntes são elementos para dar estabilidade às terças, reduzindo o comprimento de flambagem, aumentando a capacidade resistente da terça à compressão. As correntes irão funcionar como tirantes que apoiarão as terças na direção de menor resistência, no qual foi adotado perfil L 1" x 1/8".

As correntes são fixadas em pontos rígidos para poderem transmitir a estas os esforços naquela direção.

No caso da última terça, a que fica na cumeeira da cobertura, não há como ligá-la através do tirante formado pela "corrente". Neste caso usa-se um elemento rígido, chamada de "corrente rígida", composta por um perfil U 100 x 50 x 4,75.

Na Tabela 12 são apresentados o esforço axial solicitante e o respectivo aproveitamento da seção.

Tabela 12 - Solicitação de cálculo nas correntes.

\begin{tabular}{ccc}
\hline ELEMENTO & $\mathbf{N}_{\mathbf{d}}(\mathbf{k N})$ & APROVEITAMENTO $(\boldsymbol{\%})$ \\
\hline Corrente flexível & 5,995 & 19,5 \\
Corrente rígida & 6,000 & 10,0 \\
\hline
\end{tabular}

Fonte: Autores (2021).

\subsection{Barras de travamento}

Faz-se necessário o uso de barras de travamento para estabilidade lateral do banzo inferior da treliça. Da mesma forma que as correntes, são utilizadas para diminuir o comprimento de flambagem em relação ao eixo de menor inércia, são também necessárias o uso de barras rígidas entre as duas últimas treliças em ambas extremidades as quais são formadas por um treliçado composto por um perfil U enrijecido (UDC 200 x 75 x 25 x 3) como banzo e diagonais e montante sendo perfil U simples (U 100 x 50 x 4,75). As barras que funcionam como tirantes são compostos por cantoneiras L 1" x 1/8". Na Tabela 13 são apresentados os esforços axiais solicitantes e os respectivos aproveitamentos das seções.

Tabela 13 - Solicitação de cálculo nas barras de travamento.

\begin{tabular}{ccc}
\hline ELEMENTO & $\mathbf{N}_{\mathbf{d}}(\mathbf{k N})$ & APROVEITAMENTO (\%) \\
\hline Cantoneiras L 1" x 1/8” & 10,24 & 33,4 \\
UDC 200 x 75 × 25 × 3 & 9,50 & 23,4 \\
U $100 \times 50$ x 4,75 & 11,73 & 90,4 \\
\hline
\end{tabular}

Fonte: Autores (2021).

\subsection{Ligações}

Nesta seção são apresentadas as ligações calculadas conforme prescrições normativas, item 6 na ABNT NBR 8800:2008 para os perfis laminados e item 10 da ABNT NBR 14762:2010 para os perfis formados a frio. Frisa-se que em busca de melhor qualidade na execução de ligações, soldas em campo são preferencialmente evitadas, além de se ter maior agilidade e praticidade quando se utilizam ligações parafusadas na obra. 
Research, Society and Development, v. 10, n. 8, e54810817765, 2021

(CC BY 4.0) | ISSN 2525-3409 | DOI: http://dx.doi.org/10.33448/rsd-v10i8.17765

\subsubsection{Ligação viga-pilar}

As ligações viga-pilar foram realizadas através de ligações rígidas. Para as vigas que se ligam na mesa do pilar, a ligação foi efetuada com uma chapa soldada na extremidade da viga, a qual é parafusada no pilar (Figura 13). Já para ligação de vigas na alma do pilar, utilizou-se de cantoneira de alma parafusada no pilar e na viga para transferência de esforço cortante e normal e para a transferência de momentos foi realizada através da conexão parafusada das mesas em chapas soldas no pilar (Figura 14).

Figura 13 - Ligação viga-pilar por chapa de extremidade.

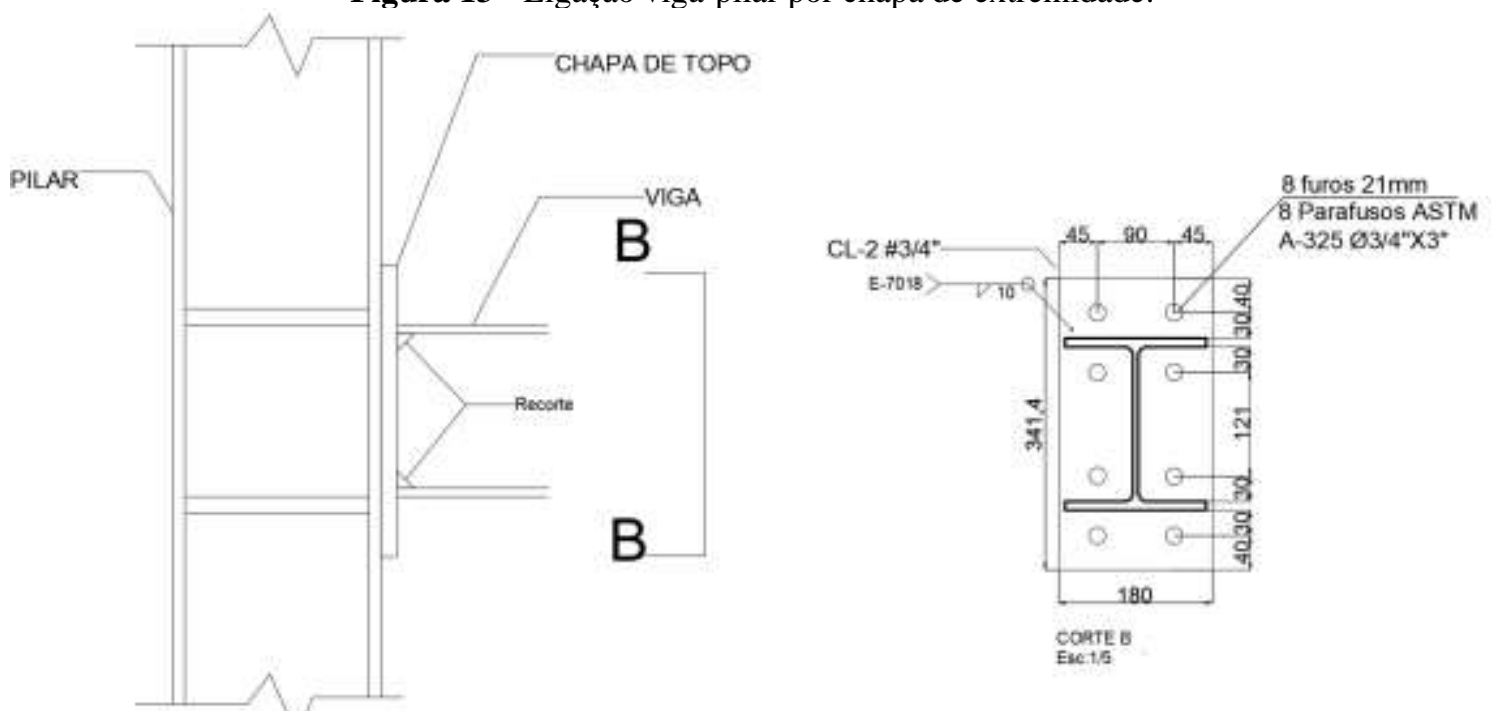

Fonte: Autores (2021). 
Research, Society and Development, v. 10, n. 8, e54810817765, 2021

(CC BY 4.0) | ISSN 2525-3409 | DOI: http://dx.doi.org/10.33448/rsd-v10i8.17765

Figura 14 - Ligação viga-pilar por cantoneira de alma e enrijecedores.



Fonte: Autores (2021).

\subsubsection{Ligação treliça-pilar}

A treliça foi ligada ao pilar através de chapa de extremidade soldada ao montante e parafusada ao pilar conforme a Figura 15.

Figura 15 - Ligação Treliça-Pilar.

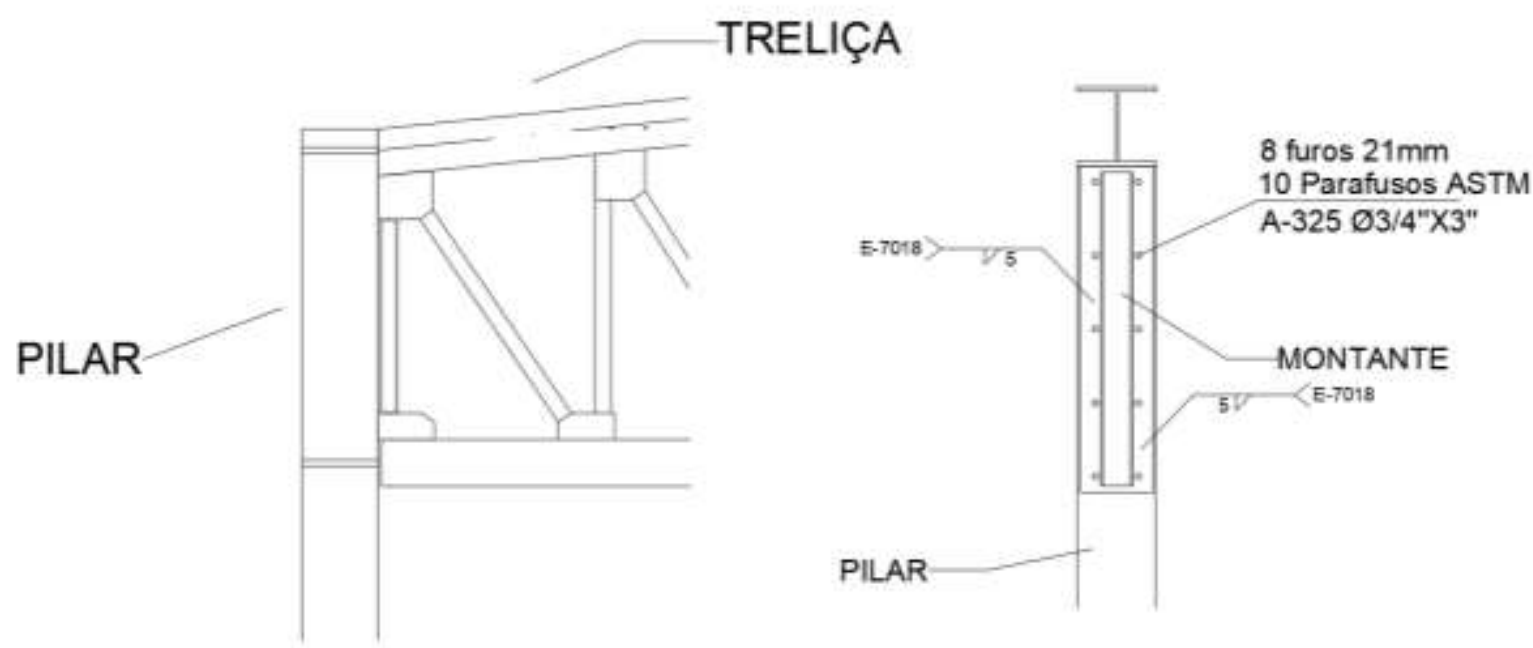

Fonte: Autores (2021). 


\subsubsection{Ligação pilar-fundação}

As ligações das bases dos pilares foram consideradas articuladas e foram realizadas através de chumbadores dimensionados conforme método AISC (Fisher; Klaiber, 2006) conforme a Figura 16 abaixo.

Figura 16 - Ligação das bases dos pilares.
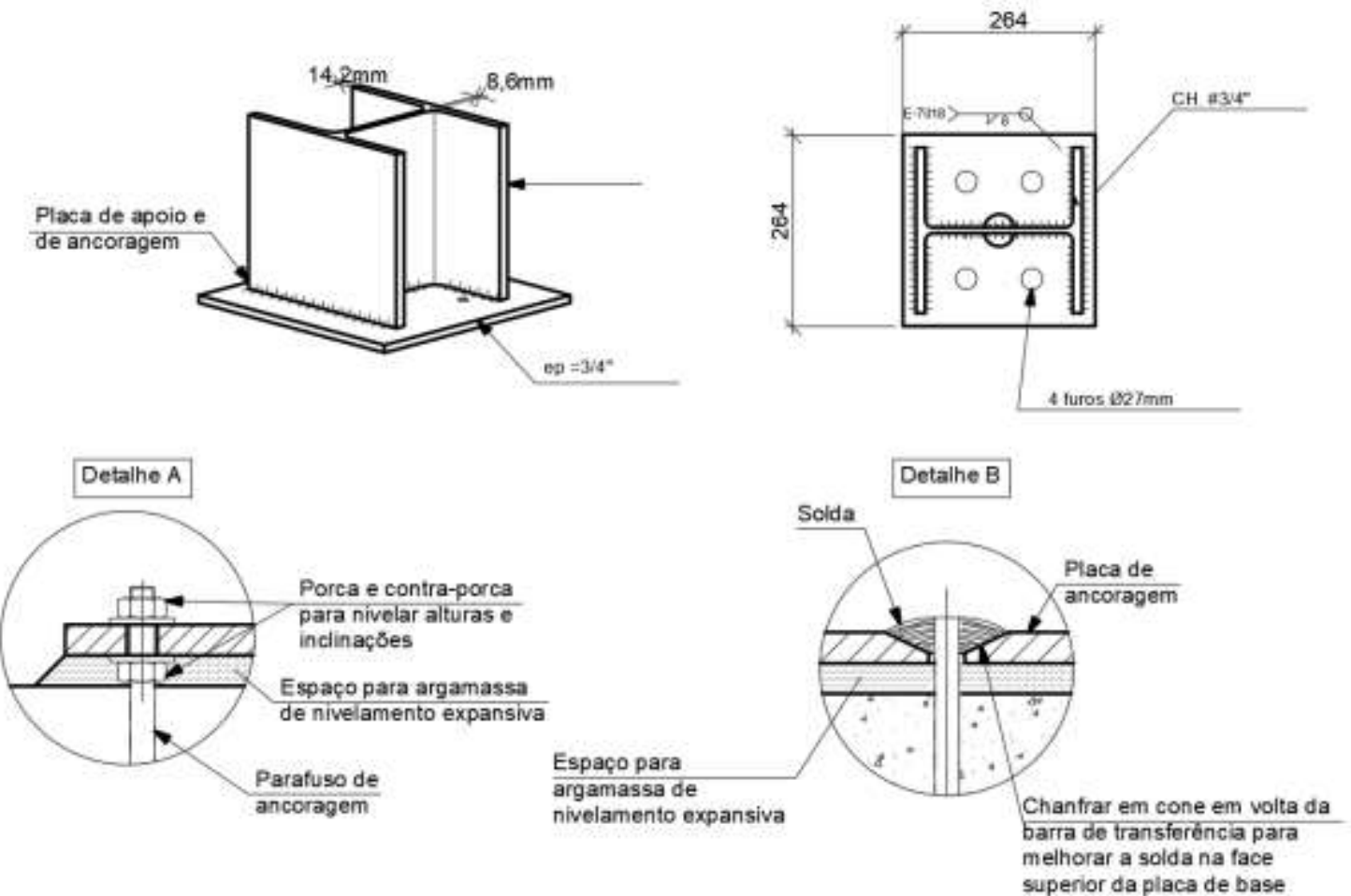

Fonte: Autores (2021).

\subsubsection{Ligação terça-treliça}

A ligação da terça na treliça foi calculada através da combinação de cantoneiras parafusas no banzo superior e na alma da terça, com soldas conforme Figura 17 e 18.

Figura 17 - Detalhe de ligação entre terças.


Fonte: Autores (2021). 
Figura 18 - Ligação das terças nos banzos.
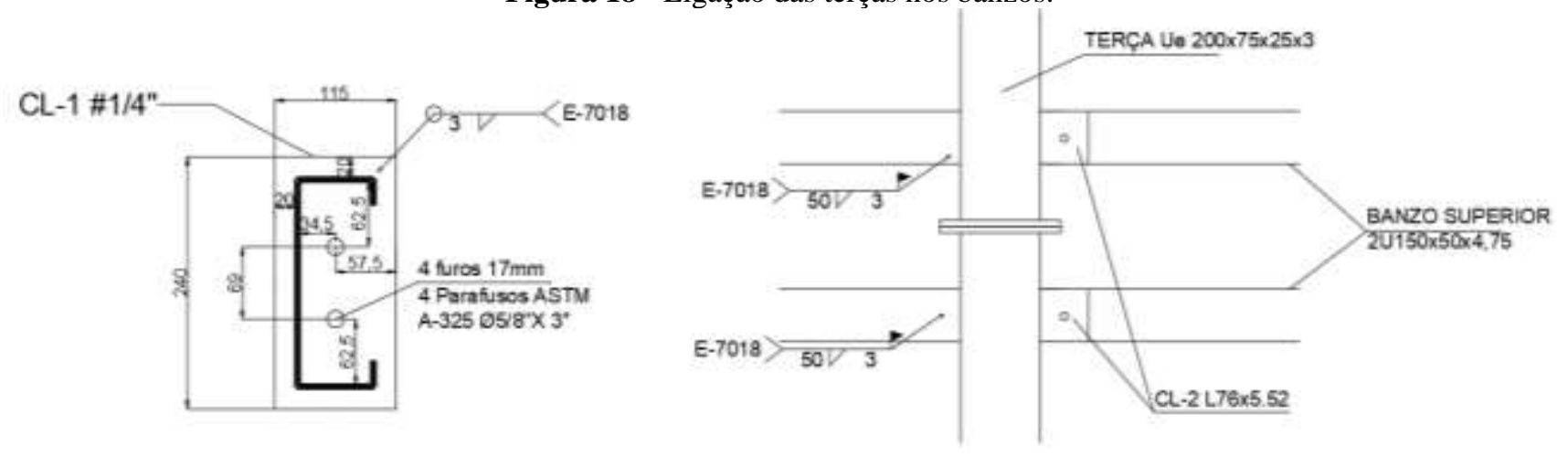

Fonte: Autores (2021).

\subsubsection{Emenda da treliça}

A emenda na treliça foi efetuada através de parafusos entre chapas de extremidade soldadas nos banzos junto com a solidarização do montante com presilhas conforme Figura 19.

Figura 19 - Ligação da emenda da treliça.

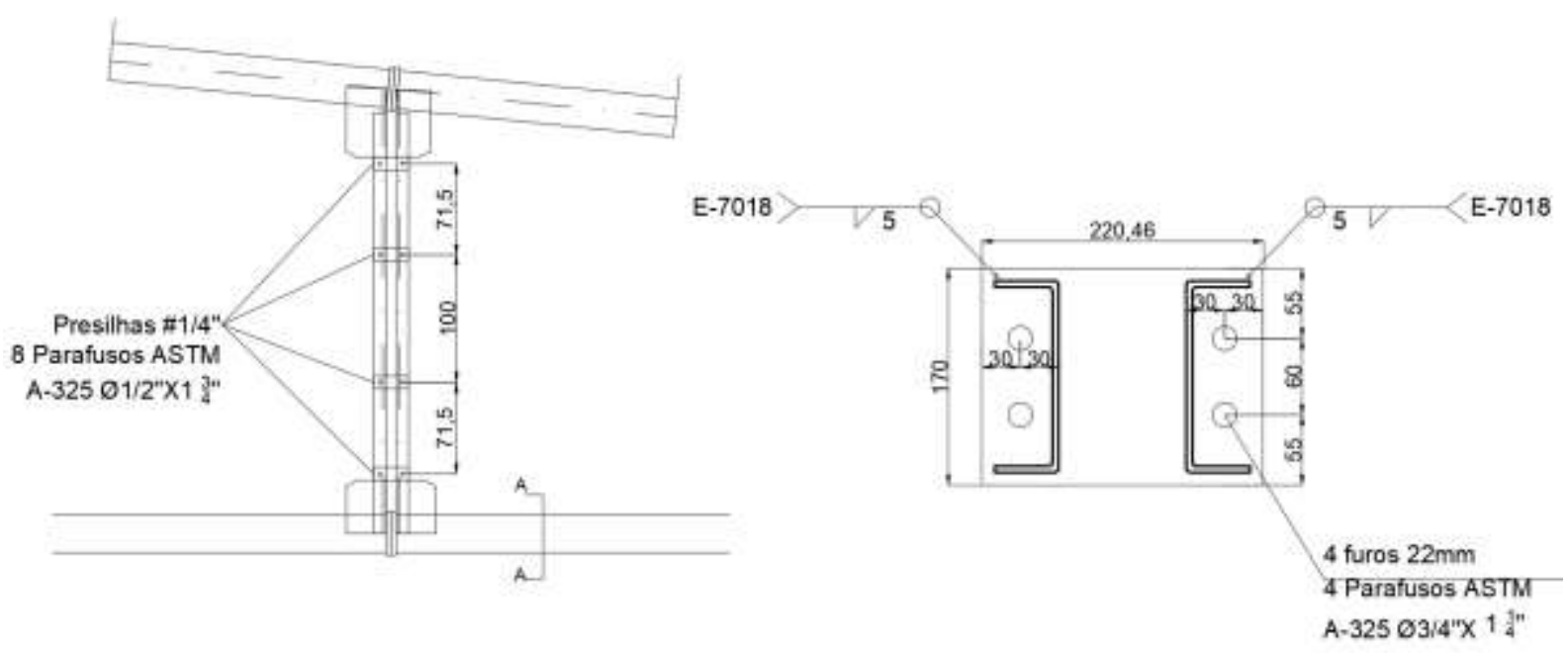

Fonte: Autores (2021).

\subsection{Quantitativo de materiais}

Nas Tabelas 14 e 15 abaixo encontram-se o quantitativo de perfis de aço, o comprimento das seções e o peso total de aço utilizado no galpão e os quantitativos de parafusos, arruelas e porcas. 
Tabela 14 - Quantitativo de perfis de aço.

\begin{tabular}{cccc}
\hline & \multicolumn{3}{c}{ Quantitativo de aço } \\
\hline Perfil & Peso Unitário $(\mathrm{kg} / \mathrm{m})$ & Comprimento total $(\mathrm{m})$ & Peso $(\mathrm{kg})$ \\
U $100 \times 50 \times 4,75$ & 6,87 & 1353,7532 & 9300,28 \\
UDC $200 \times 75 \times 25 \times 32$ & 8,95 & 1095,480 & 9804,55 \\
U $150 \times 50 \times 4,75$ & 8,73 & 1042,624 & 9102,11 \\
W 200 × 35,9 & 35,9 & 145,7788 & 5233,46 \\
W 250 x 73 & 73 & 188 & 13724,00 \\
L $88,9 \times 8,56$ & 8,56 & 745,6272 & 6382,57 \\
L 25,4 x 1,19 & 1,19 & 1076,9976 & 1281,63 \\
& & Peso total $(\mathrm{kg})$ & 54828,59 \\
\hline
\end{tabular}

Fonte: Autores (2021).

Tabela 15 - Quantitativo de parafusos, porcas e arruelas.

\begin{tabular}{|c|c|c|c|}
\hline \multicolumn{4}{|c|}{ Quantitativo } \\
\hline & Diâmetro (pol) & Comprimento (pol) & Quantidade (un) \\
\hline \multirow{6}{*}{ Parafusos } & $1 / 2^{\prime \prime}$ & $13 / 4 "$ & 1156 \\
\hline & \multirow{2}{*}{$5 / 8^{\prime \prime}$} & $2^{\prime \prime}$ & 288 \\
\hline & & $21 / 4 "$ & 468 \\
\hline & \multirow{2}{*}{$3 / 4 "$} & $3 "$ & 264 \\
\hline & & $31 / 4 "$ & 160 \\
\hline & $11 / 8 "$ & $3 \% "$ & 144 \\
\hline \multirow{5}{*}{ Porcas } & \multicolumn{2}{|r|}{$1 / 2^{\prime \prime}$} & 1156 \\
\hline & \multicolumn{2}{|r|}{$5 / 8^{\prime \prime}$} & 756 \\
\hline & \multicolumn{2}{|r|}{$3 / 4 "$} & 424 \\
\hline & \multicolumn{2}{|c|}{$11 / 8 "$} & 144 \\
\hline & \multicolumn{2}{|c|}{ Espessura (mm) } & Quantidade (un) \\
\hline \multirow{3}{*}{ Arruelas lisas } & \multicolumn{2}{|r|}{4} & 1156 \\
\hline & \multicolumn{2}{|r|}{6} & 1180 \\
\hline & \multicolumn{2}{|r|}{9,5} & 144 \\
\hline \multirow{3}{*}{ Arruelas de pressão } & \multicolumn{2}{|r|}{4} & 2312 \\
\hline & \multicolumn{2}{|r|}{6} & 2360 \\
\hline & \multicolumn{2}{|r|}{9,5} & 288 \\
\hline
\end{tabular}

Fonte: Autores (2021).

\section{Considerações Finais}

O dimensionamento da estrutura de aço mostrou-se complexo e foi necessário extrema cautela principalmente nas verificações de ligações, pois estes ocorrem sem aviso e são grande parte do colapso de estruturas de aço.

Referente as treliças, é importante ter cuidado na determinação do comprimento de flambagem nos banzos em torno do eixo de maior inércia e o comprimento de flambagem por torção que é igual a distância entre nós da treliça, já o comprimento de flambagem em torno do eixo de menor inércia para os banzos dependerá do sistema de contraventamento no plano do telhado para o banzo superior e pelas barras de travamento no banzo inferior adotado pelo calculista. 
Os banzos estão com aproveitamento abaixo de $50 \%$ devido ao fato de que na verificação de perfil solidarizado, o perfil simples deve atender a carga de compressão para um comprimento de flambagem igual ao espaçamento entre os travejamentos, que no caso deste trabalho, resultou em $91,6 \%$ da capacidade do perfil.

Em relação às terças, para reduzir o comprimento de flambagem por torção, as terças foram unidas continuamente através de chapas de extremidade conforme detalhe $\mathrm{N} 3$ em anexo.

Normalmente, as vigas dos pórticos que estão com o contraventamento em X são ligadas ao pilar como ligações rotuladas, neste projeto não foi possível realizar desta forma pois a verificação de serviço não era atendida, tornando como ligação rígida, a flecha foi reduzida drasticamente e satisfez o requisito estabelecido por norma.

Tornou-se necessário realizar a emenda da treliça devido as questões logísticas como transporte, além dos elementos serem vendidos em comprimentos de $12 \mathrm{~m}$.

Por se tratar de um estudo de caso, sugere-se para trabalhos futuros, analisar os custos associados a esta solução estrutural, seguido de um plano de pintura e controle de qualidade para garantir a vida útil da estrutura.

\section{Referências}

ABNT. (2019) - Associação Brasileira de Normas Técnicas. NBR 6120:2019 - Ações para o cálculo de estruturas de edificações.

ABNT. (1988) - Associação Brasileira de Normas Técnicas. NBR 8681:1988 - Forças devido ao vento em edificações.

ABNT. (2003) - Associação Brasileira de Normas Técnicas. NBR 8681:2003 - Ações e segurança nas estruturas - Procedimento.

ABNT. (2008) - Associação Brasileira de Normas Técnicas. NBR 8800:2008 - Projeto de estruturas de aço e de estruturas mistas de aço e concreto de edifícios.

ABNT. (2010) - Associação Brasileira de Normas Técnicas. NBR 14762:2010 - Dimensionamento de estruturas de aço constituídas por perfis formados a frio.

Bellei, I. H., Pinho, F. O., \& Pinho, M. O. (2008). Edifícios de múltiplos andares em aço. Pini, 2, 558.

CBCA. (2020). Centro Brasileiro de Construção em Aço. O sucesso do aço na construção civil. Arquitetura \& Aço, $57,70-81$.

Centro Brasileiro da construção em aço. (2015). Evolução e perspectivas da construção em aço no Brasil. Arquitetura \& Aço, $42,60-61$.

Computers and Structures Inc. (2020). SAP2000 (Version. 20.2.0). Structural Analysis Program.

Fakury, R. H., Silva, A. L. R. D. C. E., \& Caldas, R. B. (2016). Dimensionamento de elementos estruturais de aço e mistos de aço e concreto. Pearson Education do Brasil.

Flick, U. (2009). Desenho da pesquisa qualitativa. Artmed.

Fisher, J. M., \& Klaiber, L. A. (2006). Base plate and anchor rod design. Steel Design Guide 1. American Institute of Steel Construction.

GERDAU. (2020). Perfis GERDAU - Construção metálica: tabela de bitolas. Tabela de Bitolas. https://www2.gerdau.com.br/catalogos-e-manuais.

Google Earth-Mapas (2021). http://mapas.google.com.

GRAVIA. (2013). Catálogo Técnico. https://www.gravia.net.br/industria-de-perfilados/download/catalogo-tecnico-2013.pdf.

KINGSPAN ISOESTE. (2020). Catálogos de produtos. https://downloads.kingspan-isoeste.com.br/catalogos/Linha-de-Produtos.pdf.

Malhotra, N., Rocha, I., \& Laudisio, M.C. (2005). Introdução à Pesquisa de Marketing. Pearson Prentice Hall.

MEDABIL. (2020) Mitos e Verdades sobre estruturas metálicas na construção civil. https://www.medabil.com.br/tudo-sobre-construcao-com-aco.

Pereira, A. S., Shitsuka, D. M., Parreira, F. J. \& Shitsuka, R. (2018). Metodologia da pesquisa científica. UAB/NTE/UFSM.

Pillar, R. V. (2013). Estudo de viabilidade de cobertura metálica com alternativas em perfis formados a frio, laminados abertos ou tubulares. Universidade Federal do Rio de Janeiro. p. 83.

Xerez Neto, J., \& Cunha, A. S. (2020). Estruturas metálicas: manual prático para projetos, dimensionamento e laudos técnicos. Oficina de Textos, 2, 448. 